DOI 10. 18307/2020. 0517

(c) 2020 by Journal of Lake Sciences

\title{
环太湖江苏段入湖河道污染物通量与湖区水质的响应关系”
}

\author{
吕 文 $^{1}$, 杨 惠 ${ }^{1}$, 杨金艳 ${ }^{1 * *}$,马 倩 $^{2}$, 高晓平 ${ }^{1}$, 蒋如东 ${ }^{3}$, 王晓杰 ${ }^{4}$, 徐 勇 $^{1}$, 聂 青 $^{2}$ \\ (1: 江苏省水文水资源勘测局苏州分局,苏州 215011) \\ $(2$ : 江苏省水文水资源勘测局,南京 210029) \\ (3: 江苏省水文水资源勘测局无锡分局, 无锡 214031) \\ (4:江苏省水文水资源勘测局常州分局, 常州 213022)
}

\begin{abstract}
摘 要: 基于 2008-2018 年环太湖江苏段人湖河道污染物通量及湖区水质数据,从时空变化及相关关系两个方面探讨 了人湖污染物通量与湖区水质的响应关系, 并分析了污染物进人湖体影响水质的主要因子. 结果表明: 太湖污染减排已 见成效,氨氮、总氮、高锰酸盐指数和化学需氧量人湖污染物通量整体呈下降趋势,年均下降率分别为 $8.0 \% 、 2.0 \% 、 1.6 \%$ 和 $2.2 \%$, 湖体氨氮和总氮时间格局响应较好, 年均下降率分别为 $2.1 \%$ 和 $2.3 \%$. 湖体氨氮、总氮、总磷、高锰酸盐指数和化 学需氧量与人湖污染物通量整体由西北部、西部湖区向东南部、东部湖区递减, 空间格局上响应基本一致. 全湖区年尺度 总氮、氨氮浓度与人湖河道污染物通量分别呈显著正相关、极显著正相关关系; 影响湖区总氮、氨氮的主要因子为人湖河 道的总氮、氨氮浓度,其次为人湖河道浓度与原湖区水质差值, 因此亟需加强入湖河道水质浓度的控制.
\end{abstract}

关键词 : 污染物通量;太湖;水质;环太湖人湖河道

\section{Relationship between water quality in Lake Taihu and pollutant fluxes of the rivers sur- rounding Lake Taihu in Jiangsu Province*}

LV Wen ${ }^{1}$, YANG Hui ${ }^{1}$, YANG Jinyan ${ }^{1 * *}$, MA Qian ${ }^{2}$, GAO Xiaoping ${ }^{1}$, JIANG Rudong ${ }^{3}$, WANG Xiaojie ${ }^{4}$, XU Yong ${ }^{1}$ \& NIE Qing ${ }^{2}$

( 1: Suzhou Substation of Jiangsu Province Hydrology and Water Resources Investigation Bureau, Suzhou 215011, P.R.China)

(2: Jiangsu Province Hydrology and Water Resources Investigation Bureau, Nanjing 210029, P.R. China)

(3: Wuxi Substation of Jiangsu Province Hydrology and Water Resources Investigation Bureau, Wuxi 214031, P.R.China)

( 4: Changzhou Substation of Jiangsu Province Hydrology and Water Resources Investigation Bureau, Changzhou 213022, P.R. China)

\begin{abstract}
Based on pollutant fluxes of the rivers surrounding Lake Taihu in Jiangsu Province and water quality in Lake Taihu, the response relationship between pollutant fluxes of the rivers and water quality in lake was studied from two aspects of temporal and spatial variation and correlation, main factors that affected water quality were analysed after pollutants discharged into lake. The results showed that the temporal distribution of total nitrogen $(\mathrm{TN})$ and ammonia nitrogen $\left(\mathrm{NH}_{3}-\mathrm{N}\right)$ concentrations in Lake Taihu were in good accordance with distribution of $\mathrm{TN}$ and $\mathrm{NH}_{3}-\mathrm{N}$ fluxes in river channels. $\mathrm{TN}$ and $\mathrm{NH}_{3}-\mathrm{N}$ concentrations in the lake declined since 2008, with the decrease rate per year of $2.1 \%$ and $2.3 \%$, respectively. The year descending rates of annual influxes of $\mathrm{NH}_{3}-\mathrm{N}, \mathrm{TN}, \mathrm{COD}_{\mathrm{Mn}}$ and $\mathrm{COD}_{\mathrm{Cr}}$ were $8.0 \%, 2.0 \%, 1.6 \%$ and $2.2 \%$, respectively. $\mathrm{TN}$ and $\mathrm{NH}_{3}-\mathrm{N}$ concentrations in Lake Taihu and their fluxes in river channels were positively significantly correlated. $\mathrm{NH}_{3}-\mathrm{N}, \mathrm{TN}, \mathrm{TP}, \mathrm{COD}_{\mathrm{Mn}}$ and $\mathrm{COD}_{\mathrm{Cr}}$ in the western and northwest areas were better than that in the centre, southern and eastern areas, corresponding to pollutant fluxes of the rivers. Analysis of collinearity diagnosis and multiple stepwise regression indicated that $\mathrm{TN}, \mathrm{NH}_{3}-\mathrm{N}$ concentrations in river channels, and difference values of $\mathrm{TN}, \mathrm{NH}_{3}-\mathrm{N}$ concentrations between river and lake were significantly related with water quality in the Lake Taihu. It's
\end{abstract}

* 2019-11-11 收稿;2020-02-20 收修改稿.

江苏省苏州市水利水务科技项目 (2018001) 资助.

** 通信作者; E-mail:184459173@ qq.com. 
desiderated to strengthen the control of river water quality.

Keywords: Pollutant flux; Lake Taihu; water quality; rivers surrounding the Lake Taihu

太湖是太湖流域的重要淡水资源, 也是苏州、无锡等地重要饮用水源地, 其水环境状况直接关系居民的 饮用水安全. 作为大型浅水湖泊, 环湖河道数量众多 ${ }^{[1]}$, 河道为湖区污染物输人来源 ${ }^{[2-4]}$. 环太湖 228 条出人 湖河道中, 江苏省人湖河流占比 $74.6 \%$; 多年平均人湖水量为 108.8 亿 $\mathrm{m}^{3}$, 江苏省人湖水量占比 $76.0 \%{ }^{[5]}$. 因 此环太湖江苏段入湖河道污染物输人情况对太湖水环境尤为重要.

人湖河道污染物通量是单位时间内通过人湖河道某一过水断面的污染物质量 ${ }^{[5]}$. 不管是针对内陆水 库、湖泊、海湾等水体, 还是流域、省市边界等区域, 估算河道污染物通量, 都可以为区域污染物总量控制、水 环境保护提供技术支撑 ${ }^{[6]}$. 目前太湖地区, 已有学者阐明污染物出入湖输移速率 ${ }^{[7]}$, 计算环太湖总氮、总磷 等污染物的人出湖污染物通量 ${ }^{[3-4,8-14]}$, 分析太湖人湖河道水质与湖体水质的响应关系 ${ }^{[15-16]}$, 但缺少近 10 年 时间序列的污染物通量变化以及污染物通量与湖体水质的关系方面的分析. 本文主要基于太湖水质及人湖 污染物通量的时空变化特征, 从不同时空尺度来探讨人湖河道污染物通量与湖区水质的响应关系, 并分析 人湖污染物进人湖体后影响水质的主要因子,一方面可以检验太湖污染减排成效,另一方面可以找出影响 太湖水质的主控因子,为其水环境改善提供技术依据和决策支撑.

\section{1 材料与方法}

\section{1 监测站点布设}

1.1.1 水量站点 根据环太湖水系特点建立巡测工作方案,将沿湖巡测分成若干段. 江苏境内共布设 8 段 11 站 111 个口门,其中无锡 3 段 7 站共 46 个进出水口门,苏州 5 段 2 站共 63 个进出水口门, 常州 2 个单站, 江 苏段共设单站、基点站 19 个(图 1 , 表 1 ).

1.1.2 水质站点 环太湖河道水质断面的设置考虑水质水量须同步实施监测的因素, 水质监测站点布设尽量 与水量巡测断面一致, 同时考虑目前部分沿湖小闸段一直处于关闭状态, 基本不存在与太湖进行水量交换 的情况, 本文分析中水质站意义不大. 因此, 环太湖江苏段出人湖河流设置水质站点 84 处, 其中苏州 53 处, 无锡 27 处, 常州 4 处. 太湖湖体水质断面共设置 25 个, 根据太湖分区 ${ }^{[1]}$, 湖西区 1 个、竺山湖 1 个、梅梁湖 4 个、贡湖 5 个、东部沿岸区 7 个、东太湖 3 个和湖心区 4 个(图 1 ).

\section{2 监测项目}

1.2.1 水量监测 水量监测项目为水位、流量、流向. 基点站和单站每日定时流量测验. 各巡测段流量测定频 次为 2008 、2009 年汛期 2 次/月,非汛期 1 次/月. 自 2010 年开始每月上、下旬各 1 次. 计算污染物通量的水 量数据采用整编后的资料.

1.2.2 水质监测 参与河道污染物通量计算的水质监测项目为氨氮、总磷、总氮、高锰酸盐指数、化学需氧量 浓度, 湖区加测叶绿素 $a$ 浓度. 水质化验方法均采用国家标准分析方法:氨氮浓度测定采用纳氏试剂分光光 度法 (HJ 535-2009), 总氮浓度测定采用碱性过硫酸钾消解紫外分光光度法 (HJ636-2012), 总磷浓度测定 采用钿酸铵分光光度法 (GB/T $11893-1989)$, 高锰酸盐指数测定采用酸性高锰酸钾法 ( GB/T $11892-$ 1989), 化学需氧量测定采用小型密封管法 ( ISO 15705-2002), 叶绿素 $a$ 浓度测定采用分光光度法 (SL 882012 ). 水质监测频次为 2008 、2009 年 1 次/月,自 2010 年开始每月上、下旬各 1 次.

\section{3 污染物通量计算方法}

污染物通量采用时段平均浓度 $C_{i}$ 与时段水量 $K \cdot Q_{i}$ 之积进行估算 :

$$
W=\sum_{i=1}^{n} K \cdot Q_{i} \cdot C_{i}
$$

式中, $W$ 为估算时间段的污染物通量, $n$ 为估算时间段内的采样次数, $K$ 为时段转化系数, $Q_{i}$ 为瞬时流量, $C_{i}$ 为样品 $i$ 的浓度.

\section{4 数据处理方法}

1) 运用 ArcGIS 10.1 软件进行反距离空间插值,获得湖区水质的空间变化特征,用不同颜色分级表示人 


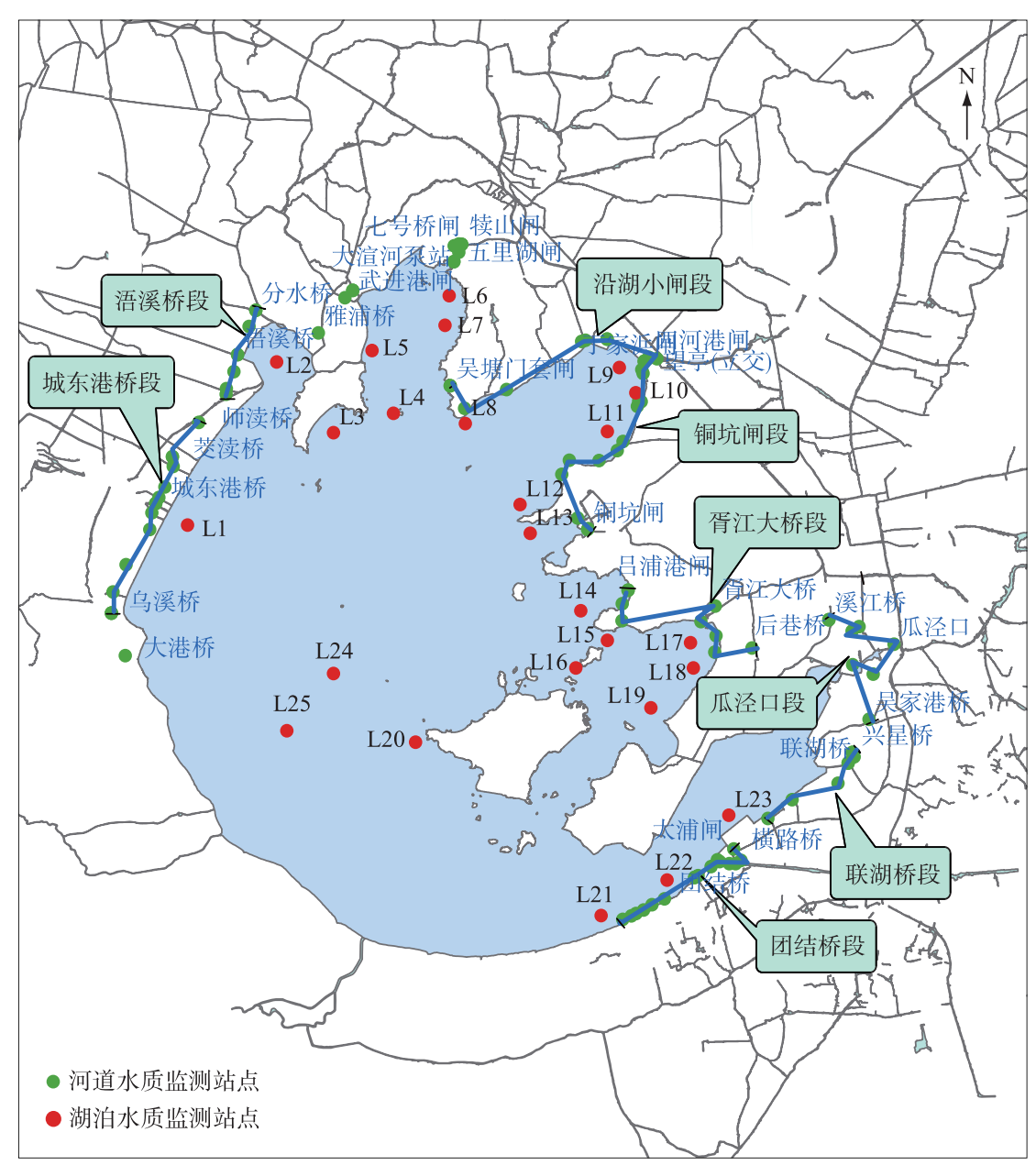

图 1 环太湖江苏段水量巡测、水质监测及太湖水质监测站点布设

Fig.1 Distribution of the monitoring sites of water quality in Lake Taihu, water quality and quantity of rivers surrounding Lake Taihu in Jiangsu Province

湖河道污染物通量大小.

2) 基于 SPSS 16.0 软件标准化处理河道人湖污染物通量和湖区水质,并进行相关性分析; 共线性诊断排 除因子共线性,进行多元逐步回归分析.

\section{2 结果与分析}

\section{1 入湖污染物通量与湖区水质的时空变化响应}

环太湖江苏段河道人湖水量、水质及污染通量与太湖水质的年际变化如图 $2 、 3$ 所示. 本文进行空间变 异分析时, 选取起始年 2008 年和终止年 2018 年, 并且依据江苏省太湖流域 1956- 2016 年年降水量频率分 析结果, 特枯年 $P=95 \%$ 保证率降水量为 $867.5 \mathrm{~mm}$; 特丰年 $P=5 \%$ 保证率降水量为 $1516.5 \mathrm{~mm}, 2013$ 年和 2016 年分别与特枯年和特丰年降水量最为接近, 再选取 2013 年和 2016 年, 污染物通量及太湖水质空间变 化如图 4 所示.

太湖湖体氨氮和总氮浓度自 2008 年来呈现逐渐降低的变化趋势, 年均减少率分别为 $2.1 \%$ 和 $2.3 \%$; 氨 氮和总氮人湖通量也呈下降趋势, 年均减少率分别为 $8.0 \%$ 和 $2.0 \%$ (图 2, 图 3). 空间格局上, 竺山湖区为高 
值区域, 氨氮和总氮浓度分别高于 0.5 和 $3.68 \mathrm{mg} / \mathrm{L}$; 竺山湖区对应河道氨氮和总氮人湖通量最大, 年均值分 别为 $0.60 \times 10^{4}$ 和 $1.26 \times 10^{4} \mathrm{t}$, 而贡湖、东部沿岸区和东太湖对应河道以出湖为主, 人湖污染物通量最低(图 $4)$. 湖区氨氮、总氮浓度和氨氮、总氮人湖污染物通量整体均呈下降趋势, 空间响应特征基本一致.

表 1 环太湖江苏段巡测段、站情况 *

Tab.1 Segments and stations of tour gauging surrounding Lake Taihu in Jiangsu Province

\begin{tabular}{|c|c|c|c|c|c|c|}
\hline 行政区 & 段、站 & 范围 & 基点站 & 主要出人湖情况 & 控制河道 & 太湖分区 \\
\hline \multirow[t]{7}{*}{ 苏州 } & 团结桥段 & 吴溇港闸至南亭子港闸 & 团结桥 & 出湖 & 14 & 东太湖 \\
\hline & 太浦闸站 & & 单站 & 出湖 & 1 & \\
\hline & 联湖桥段 & 北亭子港支流至南厍市河 & 联湖桥 & 出湖 & 13 & \\
\hline & 瓜泾口段 & 吴家港桥至苏东运河的溪江桥 & 瓜泾口 & 出人湖 & 7 & \\
\hline & 胥江大桥段 & 张家浜至吕浦港闸 & 胥江大桥 & 出人湖 & 9 & 东部沿岸区 \\
\hline & 铜坑闸段 & 湤光运河铜坑闸至丁家浜闸 & 铜坑闸 & 出人湖 & 18 & 贡湖 \\
\hline & 望亭(立交)站 & - & 单站 & 出人湖 & 1 & \\
\hline \multirow[t]{10}{*}{ 无锡 } & 沿湖小闸段 & 吴塘门套闸至四河港闸 & 单站 & 出湖 & 16 & \\
\hline & 五里湖闸 & - & 单站 & 出湖 & 1 & 梅梁湖 \\
\hline & 梅梁湖厡站 & - & 单站 & 出湖 & 1 & \\
\hline & 犊山闸 & - & 单站 & 出湖 & 1 & \\
\hline & 大渲河葲站 & - & 单站 & 出湖 & 1 & \\
\hline & 七号桥闸 & - & 单站 & 出湖 & 1 & \\
\hline & 直湖港闸 & - & 单站 & 出湖 & 1 & \\
\hline & 浯溪桥段 & 分水桥至师渎桥 & 浯溪桥 & 人湖 & 9 & 竺山湖 \\
\hline & 城东港段 & 艾渎港的荠渎桥至乌溪桥 & 城东港桥 & 人湖 & 14 & 湖西区 \\
\hline & 大港桥 & - & 单站 & 人湖 & 1 & \\
\hline \multirow[t]{2}{*}{ 常州 } & 武进港闸 & - & 单站 & 人湖 & 1 & 梅梁湖 \\
\hline & 雅浦桥 & - & 单站 & 人湖 & 1 & 竺山湖 \\
\hline
\end{tabular}

*出人湖情况为该河道主要流向.

太湖湖体总磷浓度自 2008 年来整体呈上升趋势, 年均增长率为 $1.0 \%$; 总磷人湖污染物通量在 2016 年 出现峰值, 为 $0.24 \times 10^{4} \mathrm{t}$, 高于其他年份均值 $(27.2 \%), 2011-2013$ 年总磷污染物通量由 $0.20 \times 10^{4} \mathrm{t}$ 下降至 $0.15 \times 10^{4} \mathrm{t}$, 此时湖体总磷浓度却上升至峰值,年际变化趋势上存在部分年份呈现反向变化特点(图 2 , 图 3 ). 空间格局上, 竺山湖区和湖西区为高值区; 竺山湖区和湖西区对应河道总磷入湖污染物通量年均值分别为 $0.10 \times 10^{4}$ 和 $0.07 \times 10^{4} \mathrm{t}$, 相比其他湖区高, 而贡湖、东部沿岸区和东太湖对应河道以出湖为主, 总磷人湖污染 物通量最低 (图 4). 湖体总磷浓度与人湖总磷污染物通量空间格局基本一致.

湖区高锰酸盐指数年均值范围为 $4.2 \sim 4.9 \mathrm{mg} / \mathrm{L}$, 年际变化幅度较小, 化学需氧量起伏变化; 高锰酸盐指数 和化学需氧量人湖污染物通量整体呈下降趋势,年均减少率分别为 $1.6 \%$ 和 $2.2 \%$ (图 2, 图 3). 空间格局上, 高 锰酸盐指数和化学需氧量高值区主要为竺山湖区和湖西区, 高值区高锰酸盐指数和化学需氧量多年均值分别 为 5.5 和 $23.6 \mathrm{mg} / \mathrm{L}$; 竺山湖和湖西区对应河道高锰酸盐指数人湖污染物通量多年平均值分别为 $1.70 \times 10^{4}$ 和 $2.61 \times 10^{4} \mathrm{t}$, 化学需氧量分别为 $7.8 \times 10^{4}$ 和 $11.8 \times 10^{4} \mathrm{t}$, 相比其他湖区高, 贡湖、东部沿岸区和东太湖高锰酸盐指 数对应河道以出湖为主, 高锰酸盐指数人湖污染物通量最低 (图 4). 高锰酸盐指数和化学需氧量人湖污染物 通量空间格局与湖区水质变化趋势基本一致. 另外,湖体高锰酸盐指数高值区域范围会有所变化,梅梁湖区由 2013 年高值区域 (浓度为 $5.6 \mathrm{mg} / \mathrm{L}$ ) 逐渐转为低值区域 (浓度为 $4.1 \mathrm{mg} / \mathrm{L}$ ) ; 竺山湖区高锰酸盐指数近年也逐渐 减小, 由IV类 $(6.4 \mathrm{mg} / \mathrm{L})$ 转为而类 $(5.1 \mathrm{mg} / \mathrm{L})$; 湖西区高锰酸盐指数高值区域范围增加 (图 4$)$. 湖区高锰酸盐 指数时空变化格局与叶绿素 $a$ 浓度变化基本一致 (图 4), 可能与太湖蓝藻状况有关, 浮游植物在光合作用下产 生大量有机物, 导致叶绿素 $a$ 浓度与高锰酸盐指数值之间有良好的线性关系 ${ }^{[17]}$.

\section{2 入湖污染物通量与湖区水质的相关关系}

将河道人湖污染物通量和湖区水质进行标准化处理,再基于 SPSS 16.0 软件进行相关性分析, 结果见图 

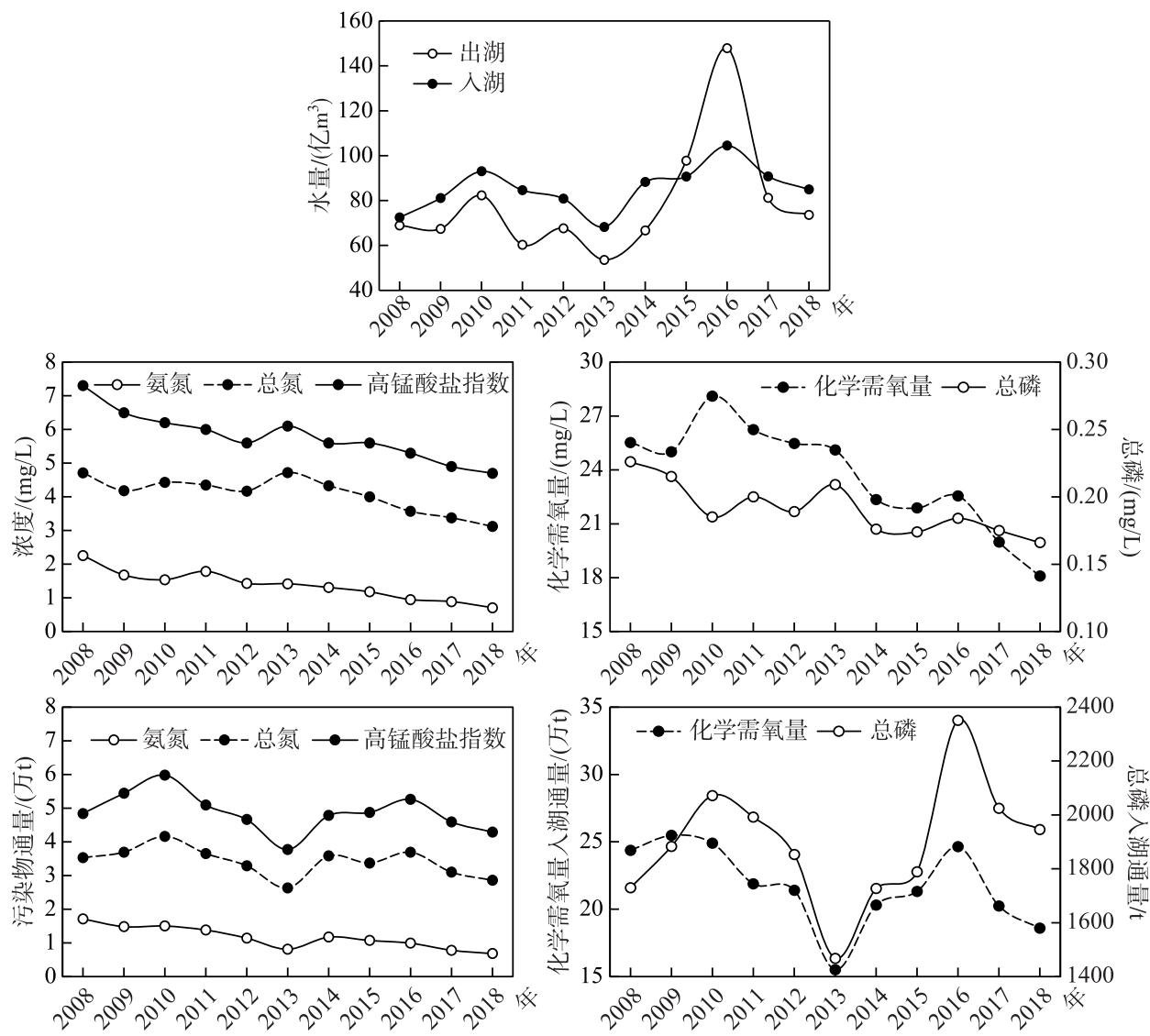

图 2 太湖人湖河道水量、水质和污染物通量的年际变化

Fig.2 Annual variations of water quality and quantity and pollutant fluxes in rivers flowing into Lake Taihu
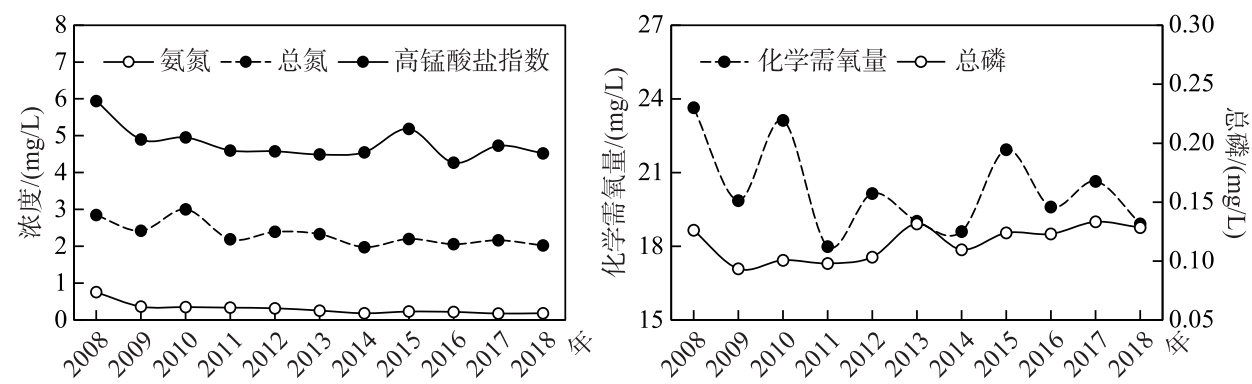

图 3 太湖水质的年际变化

Fig.3 Annual variations of water quality in Lake Taihu

5. 年尺度上, 太湖湖区总氮浓度与总氮人湖河道污染物通量呈显著正相关 $(P<0.05)$, 氨氮浓度与氨氮人湖 河道污染物通量呈极显著正相关 $(P<0.01)$, 总磷浓度、高锰酸盐指数、化学需氧量等因子无显著相关关系.

该结果表明,河道氨氮、总氮的外源输人为湖体氮营养盐的主要来源, 朱广伟 ${ }^{[16]}$ 、吴雅丽等 ${ }^{[18]}$ 的研究表 明氮是太湖主要的人湖污染物, 而且河道的氨氮和总氮浓度与湖区的比值分别为 4.5 和 2.5 , 河道与湖区浓 度差异较大, 因此, 削减人湖河道氮污染物通量对控制太湖氮素具有重要意义. 从全湖年尺度来看, 总磷浓 度与总磷人湖污染物通量的相关关系不显著, 可能与湖区底泥释放的磷对湖区水质存在影响有关 ${ }^{[19]}$, 且蓝 

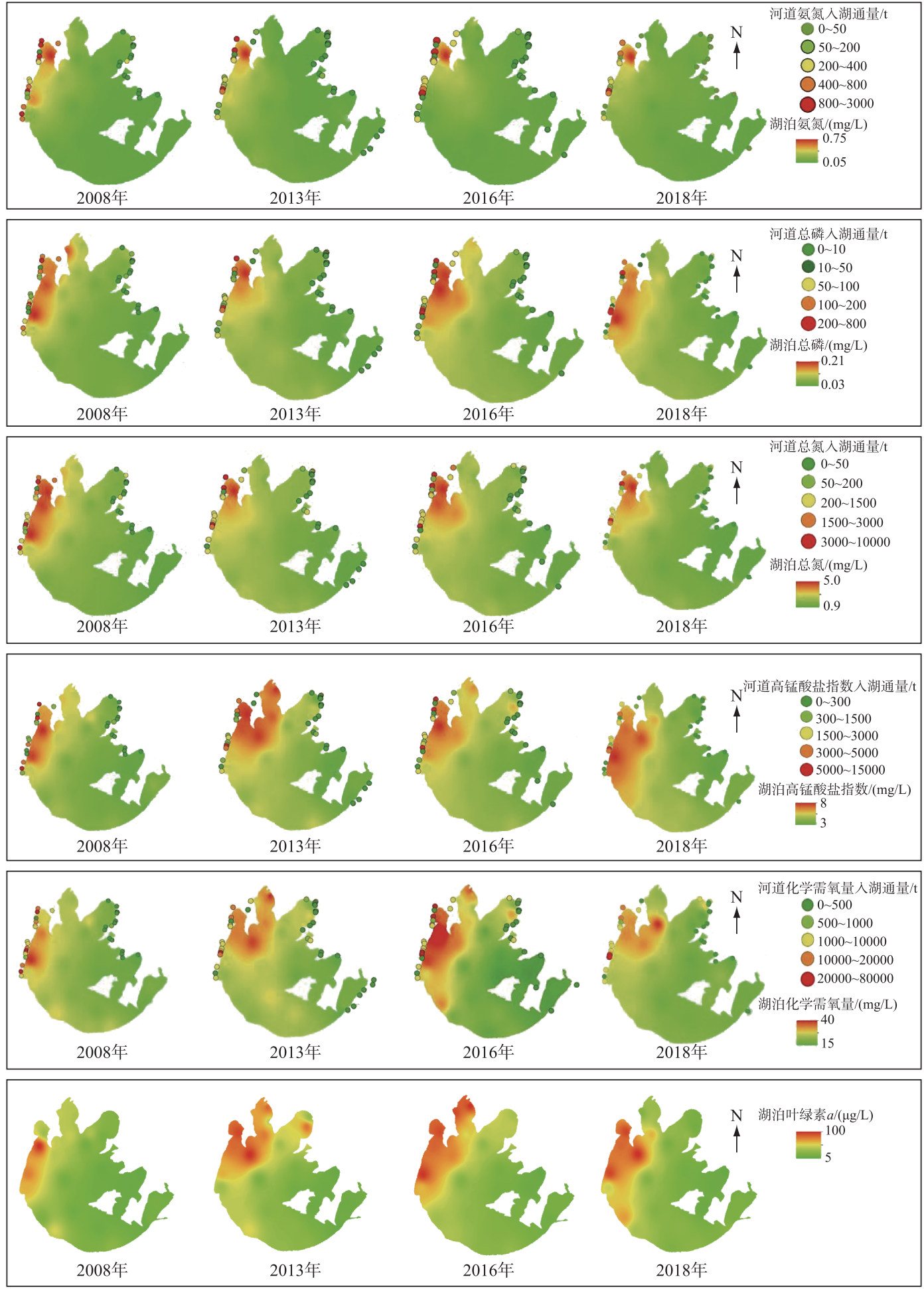

图 4 太湖水质和人湖污染物通量的时空变化

Fig.4 Spatio-temporal distribution pattern of water quality in Lake Taihu and pollutant fluxes in rivers surrounding Lake Taihu in Jiangsu Province 

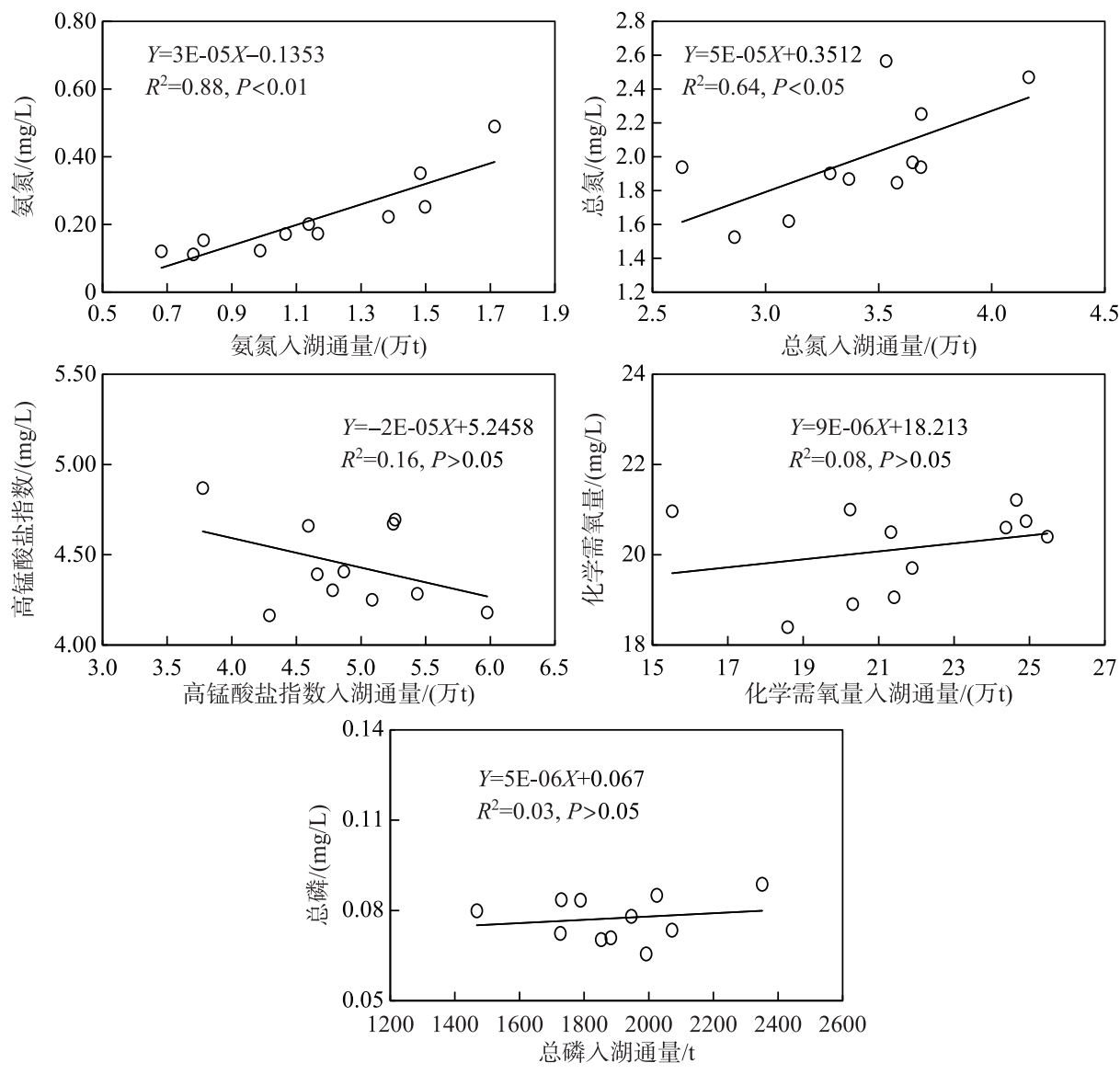

图 5 太湖水质与人湖污染物通量的相关关系

Fig.5 The correlation between water quality in Lake Taihu and pollutant fluxes in rivers surrounding Lake Taihu in Jiangsu Province

藻水华的暴发会诱导底泥磷的大量释放, 而总氮却能保持相对稳定 ${ }^{[20]}$. 另外河道总磷浓度与湖区总磷浓度 比值为 1.6 , 差异较氮素在河道、湖泊的比值小, 可能影响湖区总磷浓度对河道总磷输人的响应. 但朱广伟 ${ }^{[16]}$ 的研究认为河道磷为太湖的主要人湖污染物, 逢勇等 ${ }^{[21]}$ 估算太湖内源 TP 释放量仅相当于外源输人量的 $15.6 \%$, 总磷人湖污染物通量与湖区总磷浓度空间格局也基本一致, 总磷人湖污染物通量也需加以控制.

高锰酸盐指数和化学需氧量可以有效地反映水体有机污染的程度. 高锰酸盐指数和化学需氧量人湖通 量与湖体浓度相关性不显著, 可能是因为除河道外源输人外, 湖体高锰酸盐指数还受湖体蓝藻暴发产生的 内源污染、水位、水温等多种环境因子影响 ${ }^{[12]}$, 另外人湖河道高锰酸盐指数和化学需氧量与湖区的比值分别 为 1.31 和 1.20 , 人湖河道水质与湖区水质的差异较小, 即使高锰酸盐指数和化学需氧量人湖污染物通量大, 但由于多为水量大导致,并且人湖水量大带来了稀释效应, 可能导致两者响应关系较差.

\section{3 入湖水量、水质与湖区水质的响应关系}

人湖河道污染物进人湖体后, 水量会存在浓度稀释效应, 但河道输人的污染物质会增加湖体总污染负 荷, 污染物通量中水量、水质、通量与湖区水质的关系有待研究. 选取年尺度全湖区人湖河道水质浓度 $\left(\mathrm{TN}_{\mathrm{R}}\right)$ 、入湖水量 $(\mathrm{Q})$ 、湖区水位 $(\mathrm{WL})$ 、入湖水质浓度与原湖泊水质浓度差值 $(\mathrm{D})$, 基于 SPSS 16.0 软件进行 因子共线性诊断, 排除因子共线性, 建立多元逐步回归方程, 篮选因子, 探讨人湖污染物通量进人后影响湖 区水质的主要因子. 
结果表明, 影响湖区总氮的主要因子为 $\mathrm{TN}_{\mathrm{R}}$, 其次为人湖河道与原湖区水质差值 $\left(\mathrm{D}_{\mathrm{TN}}\right)$; 影响湖区氨氮 的主要因子为人湖河道的氨氮浓度 $\left(\mathrm{NH}_{3}-\mathrm{N}_{\mathrm{R}}\right)$, 其次为人湖河道与原湖区水质差值 $\left(\mathrm{D}_{\mathrm{NH}_{3} \mathrm{~N}}\right)$; 湖区总磷、高锰 酸盐指数和化学需氧量无显著影响因子 (表 2). 总氮和氨氮相比湖区偏高的河道水体进人湖区, 与总磷、高 锰酸盐指数和化学需氧量相比湖区浓度差异偏小的河道水体进人湖区, 湖区水体各项水质参数响应存在 差异.

\section{表 2 太湖湖区水质因子多元逐步回归结果 *}

Tab.2 Analysis of collinearity diagnosis and multiple stepwise regression of water quality in Lake Taihu

\begin{tabular}{ccccc}
\hline 因变量 & 人选因子 & 共线性诊断 & 逐步回归方程 & 相关系数 \\
\hline \multirow{2}{*}{$\mathrm{TN}$} & $\mathrm{TN}_{\mathrm{R}}$ & $T o l i=0.7$ & $(1) \mathrm{TN}_{\mathrm{L}}=0.194+0.440 \mathrm{TN}_{\mathrm{R}}$ & $0.719(P<0.05)$ \\
& $\mathrm{D}_{\mathrm{TN}}$ & $V I F=1.5$ & 2 2) $\mathrm{TN}_{\mathrm{L}}=0.174+0.654 \mathrm{TN}_{\mathrm{R}}-0.440 \mathrm{D}_{\mathrm{TN}}$ & $0.870(P<0.01)$ \\
$\mathrm{NH}_{3}-\mathrm{N}$ & $\mathrm{NH}_{3}-\mathrm{N}_{\mathrm{R}}$ & $T o l i=0.2$ & (1) $\mathrm{NH}_{3}-\mathrm{N}_{\mathrm{L}}=-0.101+0.229 \mathrm{NH}_{3}-\mathrm{N}_{\mathrm{R}}$ & $0.889(P<0.01)$ \\
& $\mathrm{D}_{\mathrm{NH}_{3}-\mathrm{N}}$ & $V I F=4$ & (2) $\mathrm{NH}_{3}-\mathrm{N}_{\mathrm{L}}=-0.023+0.420 \mathrm{D}_{\mathrm{NH}_{3}-\mathrm{N}}$ & $0.981(P<0.01)$ \\
\hline
\end{tabular}

* 总磷、高锰酸盐指数和化学需氧量无变量进人回归方程.

\section{3 结论}

1 ) 时间格局上, 太湖氨氮和总氮浓度自 2008 年呈下降趋势, 年均下降率分别为 $2.1 \%$ 和 $2.3 \%$. 氨氮、总 氮、高锰酸盐指数和化学需氧量人湖污染物通量整体呈下降趋势, 年均下降率分别为 $8.0 \% 、 2.0 \% 、 1.6 \%$ 和 $2.2 \%$. 太湖污染减排已见成效,湖体氨氮、总氮响应较好. 另外, 受水量影响人湖污染物通量呈现 2013 年特 枯年、2016 年特丰年分别位于低值、高值的特征.

2) 空间格局上,太湖氨氮浓度、总磷浓度、总氮浓度、高锰酸盐指数和化学需氧量整体呈自西部、西北部 湖区向东部、东南湖区逐渐降低的变化趋势; 西部、西北部湖区对应人湖河道污染物通量也明显高于东部、 东南部河道. 湖体水质与人湖污染物通量空间格局基本一致. 西部、西北部的人湖污染物通量大, 增加了湖 区污染物负荷, 通过太湖水体的自净, 湖心、东部、东南部湖区污染物浓度降低.

3 ) 相关性分析结果表明,年尺度上,湖区总氮、氨氮浓度与人湖总氮、氨氮污染物通量分别呈显著正相 关、极显著正相关关系; 多元逐步回归结果表明,影响湖区总氮、氨氮的主要因子为人湖河道的总氮、氨氮浓 度, 其次为人湖河道与原湖区水质差值. 环太湖人湖河道水质浓度为影响太湖水质的主控因子, 亟需加强人 湖河道水质浓度的控制.

致谢: 感谢江苏省水文水资源勘测局周毅教高、常州分局王雪松局长和无锡分局沈顺中局长的指导, 江苏省 水文水资源勘测局刘俊杰教高、姚敏高工以及南京工业大学李跃同学在数据收集和制图方面的帮助.

\section{4 参考文献}

[ 1 ] Taihu Basin Authority of Ministry of Water Resources ed. History of Lake Taihu. Beijing: China Water Power Press, 2018. [水利部太湖流域管理局, 《太湖志》编纂委员会. 太湖志. 北京: 中国水利水电出版社, 2018. ]

[ 2 ] Qin BQ, Hu WP, Chen WM et al eds. Process and mechanism of environmental changes of the Taihu Lake. Beijing: Science Press, 2004. [ 秦伯强, 胡维平, 陈伟民等. 太湖水环境演化过程与机理. 北京: 科学出版社, 2004.]

[ 3 ] Zhai SH, Zhang HJ. Water quantity and waste load variation of rivers around Lake Taihu from 2000 to 2002. J Lake Sci, 2006, 18(3) : 225-230. DOI: 10.18307/2006.0305. [翟淑华, 张红举. 环太湖河流进出湖水量及污染负荷 (20002002 年). 湖泊科学, $2006, \mathbf{1 8}(3): 225-230$.]

[ 4 ] Xu PZ, Qin BQ. Water quantity and pollutant fluxes of the surrounding rivers of Lake Taihu during the hydrological year of 2001-2002. J Lake Sci , 2005, 17(3) : 213-218. DOI: 10.18307/2005.0304. [许朋柱, 秦伯强. 2001-2002 水文年 环太湖河道的水量及污染物通量. 湖泊科学, 2005, 17(3) : 213-218.]

[ 5 ] Yang JY, Wang XS, Shen SZ et al eds. Pollutant fluxes inflow and outflow rivers of Lake Taihu. Nanjing: Hohai University Press, 2019. [ 杨金艳, 王雪松, 沈顺中等. 环太湖出人湖河道污染物通量. 南京: 河海大学出版社, 2019.]

[ 6 ] Fu G. Analysis of the estimation methods for the river pollutant fluxes ( I ): Comparison and analysis of the estimation 
methods of period fluxes. Research of Environmental Sciences, 2003, 16(1): 1-4. [富国. 河流污染物通量估算方法分 析( I ) 一一时段通量估算方法比较分析. 环境科学研究, 2003, 16(1): 1-4.]

[ 7 ] Zhu JG, Liu X, Deng JC et al. Pollutant transport rates in the rivers around western Lake Taihu. J Lake Sci, 2018, 30 (6) : 1509-1517. DOI: 10.18307/2018.0603. [ 朱金格, 刘金金, 邓建才等. 太湖西部环湖河道污染物输移速率变化 特征. 湖泊科学, $2018, \mathbf{3 0}(6)$ : 1509-1517.]

[ 8 ] He XJ, Wang B, Liu GY et al. Water quality, quantity and pollutant fluxes variations of the rivers surrounding Lake Taihu in Zhejiang Province during hydrological year of 2010-2011. J Lake Sci, 2012, 24(5) : 658-662. DOI: 10.18307/2012. 0502. [ 何锡君, 王贝, 刘光裕等. 2010-2011 水文年浙江省环太湖河道水质水量及污染物通量. 湖泊科学, 2012, 24(5): 658-662.]

[ 9 ] Ma Q, Liu JJ, Gao MY. Amount of pollutants discharged into Lake Taihu from Jiangsu Province, 1998-2007. J Lake Sci, 2010, 22(1) : 29-34. DOI: 10.18307/2010.0104. [马倩, 刘俊杰, 高明远. 江苏省人太湖污染量分析 (1998-2007 年). 湖泊科学, $2010,22(1): 29-34$.]

[10] Yan SW, Yu H, Zhang LL et al. Water quantity and pollutant fluxes of inflow and outflow rivers of Lake Taihu, 2009. J Lake Sci, 2011, 23(6) : 855-862. DOI: 10.18307/2011.0605. [燕姝雯, 余辉, 张璐璐等. 2009 年环太湖人出湖河流 水量及污染负荷通量. 湖泊科学, $2011,23(6): 855-862$. ]

[11] Luo J, Xiang Y, Lin Y et al. Study on flux of pollutants discharged into Taihu Lake through main inflow river channels. Journal of Hohai University: Natural Sciences, 2005, (2) : 131-135. [罗缙, 逢勇, 林颖等. 太湖流域主要人湖河道污 染物通量研究. 河海大学学报: 自然科学版, 2005, (2): 131-135.]

[12] Wen X, Qiu L, Zhang SS et al. Pollutant fluxes of the water diversion project and the contribution to the water quality of Taihu Lake. Sichuan Environment, 2014, 33(5): 67-71. [闻欣, 邱利, 章双双等. 引江济太入湖污染物通量及其对 太湖水质贡献. 四川环境, 2014, 33(5): 67-71.]

[13] Wu P, Qin BQ, Yu G et al. Effects of economic development on wastewater discharge and influent total phosphorus load in the upstream of Lake Taihu Basin. J Lake Sci, 2015, 27(6) : 1107-1114. DOI: 10.18307/2015.0616 [吴攀, 秦伯强, 于革等. 太湖上游流域经济发展对废水排放及人湖总磷的影响. 湖泊科学, 2015, 27(6): 1107-1114.]

[14] Chen XF , Chuai XM, Zeng J et al. Nitrogenous fluxes and its self-purification capacity in Lake Taihu. Environmental Science, 2012, 33(7) : 2309-2314. DOI: 10.13227/j.hjkx.2012.07.032. [陈小锋, 揣小明, 曾巾等. 太湖氮素出人湖通 量与自净能力研究. 环境科学, 2012, 33(7): 2309-2314.]

[15] Zha HM, Zhu MY, Zhu GW et al. Seasonal difference in water quality between lake and inflow/outflow rivers of lake Taihu, China. Environmental Science, 2018, 39(3) : 1102-1112. DOI: 10.13227/j.hjkx.201707184. [查慧铭, 朱梦圆, 朱广伟等. 太湖出人湖河道与湖体水质季节差异分析. 环境科学, 2018, 39(3) : 1102-1112.]

[16] Zhu GW. Spatio-temporal distribution pattern of water quality in Lake Taihu and its relation with cyanobacterial blooms. Resources and Environment in the Yangtze Basin, 2009, 18(5):439-445. [ 朱广伟. 太湖水质的时空分异特征及其与水 华的关系. 长江流域资源与环境, 2009, 18(5): 439-445.]

[17] Yang XS, Zhang LP. Influence of content of chlorophyll a on index determination of permanganate. Yunnan Environmental Science, 1998, (4) : 59-61. [杨晓珊, 张丽萍. 叶绿素 a 含量对高锰酸盐指数测值影响初探. 云南环境科学, 1998, (4) : 59-61.]

[18] Wu YL, Xu H, Yang GJ et al. Progress in nitrogen pollution research in Lake Taihu. J Lake Sci, 2014, 26(1) : 19-28. DOI: 10.18307/2014.0103. [ 吴雅丽, 许海, 杨桂军等. 太湖水体氮素污染状况研究进展. 湖泊科学, 2014, 26 (1) : 19-28.]

[19] Fan CX, Zhang L, Qin BQ et al. Estimation of dynamic release of phosphorus from suspended particles in Lake Taihu under the action of wind and waves. Science in China: Series D, 2003, 33(8):760-768. [范成新, 张路, 秦伯强等. 风浪 作用下太湖悬浮态颗粒物中磷的动态释放估算. 中国科学：D 辑, 2003, 33(8) : 760-768.]

[20] Xie P. Biological driving mechanism of seasonal variation of endogenous phosphorus load in shallow lakes. Science in Chi$n a$ : Series D, 2005, 35 (Supplement II ) :11-23. [谢平. 浅水湖泊内源磷负荷季节变化的生物驱动机制. 中国科学: D 辑, 2005, 35 (增刊 II ) : 11-23.]

[21] Pang Y, Yan RR, Li YP et al. Contribution of combined action of exogenous source and internal load on water nutrient in Taihu Lake. Journal of Hydraulic Engineering, 2008, 39(9) : 1051-1059. [逢勇, 颜润润, 李一平等. 内外源共同作 用对太湖营养盐贡献量研究. 水利学报, 2008, 39(9): 1051-1059.] 